\title{
Codesigning emancipatory systems: a study on mobile applications and lesbian, gay, bisexual, and transgender (LGBT) issues
}

\author{
Guilherme C. Pereira \\ Institute of Computing \\ UNICAMP \\ Campinas, Brazil \\ colucciguilherme@gmail.com
}

\author{
M. Cecilia C. Baranauskas \\ Institute of Computing \\ UNICAMP \\ Campinas, Brazil \\ cecilia@ic.unicamp.br
}

\begin{abstract}
HCI is a well-suited discipline for designing systems intended to support disenfranchised groups. The LGBT population is increasingly gaining visibility, but the range of subjects they are affected by prejudice and exclusion is wide. This work begins by a review on LGBT issues in HCI literature and mobile applications. We point out a lack of consideration of LGBT people as designers and critical approaches, explicitly aiming to not only understand but effectively act on social issues. In addition, few mobile applications disclose a critical goal, despite their potential impact on health, alterity, empathy, safety, and sociability. Then, we describe a semioparticipatory approach for codesign, focusing on the first conducted activities where the relations between mobile applications and LGBT issues were discussed with volunteers interested in the subject. Finally, we present the concept of a novel application aiming at the support and protection of LGBT people.
\end{abstract}

Keywords- LGBT; state of art; state of technique; empowerment; codesign

\section{INTRODUCTION}

Visibility of LGBT issues is increasing, as reflected by their taking into account by electoral agendas, the use of social media as an arena for sexuality and gender debates, or the recent achievement of rights in American countries. However, it does not follow that quality of life of LGBT people or social equality are universal, especially in Brazil.

It is natural that software development and, in particular, Human-Computer Interaction (HCI) research also increasingly treat related subjects. One particular approach is to seek ways of supporting LGBT people across the daily struggles. This is the goal of the project where this work is inscribed, whose intended result is a mobile application to help prevent and fight prejudice in Brazil.

Brazil is notorious for being the country with the highest amount of LGBT killing - one LGBT person each 27 hours [17], 117 people only until 2017, May 17th [12]. Such statistics are based in Non-Governmental Organizations (NGO) reports, since Brazil does not have a specific law against LGBTphobia ${ }^{1}$, so police lacks proper ways to classify them.

This paper discusses how mobile applications might impact the fight against LGBT prejudice. In section II, we briefly describe LGBT issues and disclose our philosophical stance, which we believe is helpful to proper frame our values and assumptions. Section III presents a literature review on HCI works and LGBT issues. We visit how current mobile applications relate to the subject in Section IV, where a review of Google's Play Store is presented. Section V describes a codesign methodology adopted to develop a new application targeted at supporting LGBT people. Section VI discusses the first realized activities, where the relation between mobile apps and LGBT issues is discussed by a group of volunteers, in participatory tasks. The remaining activities are summarized in Section VII, where LGBTrust, the resulting application, is described. Finally, we discuss our contributions, limitations, and suggestions of future works in Section VIII.

\section{SOCIAL CONTEXT}

\section{A. Sexual orientation and gender identity}

At the core of LGBT framework, are the terms sex, gender, and desire. The former is related to the gender assignment made based on newborns' genitalia - the sex of babies born with a penis, for instance, is said to be male. In most societies, including Brazil, people may be assigned to only two sexes, male or female. Feminist approaches state that different social roles and expectancies are placed upon individuals, according to their sex. Perhaps the most influent piece from last century is de Beauvoir's "The Second Sex", where she describes how regards to women's body changed throughout history, in order to investigate if there is an essential explanation to so-called female "body disadvantages" or if they are the product of patriarchal social phenomena [4].

This leads to the second term: "the socially imposed division of sexes" [31]. The exact nature of gender is subject of debate in social sciences and we will not further explore it. More important to this work is the sex/gender distinction,

\footnotetext{
${ }^{1}$ Here used as a generic term to prejudice towards LGBT people.
} 
firstly proposed by a psychologist, Robert Stoller [34]. Although there is also debate about misleading characteristics of this distinction, it is convenient to describe transgender people - those who self-identify with a gender which does not entirely match the sex assigned at birth. For the opposite case, the neologism cisgender is used. The $\mathrm{T}$ in LGBT accounts for transgender people.

Finally, sexual orientation is related to one's gender and the gender of people to whom one feels emotionally or sexually attracted - the object of desire. The LGB segment encompasses non-heterosexual people, i.e., people who do not feel attracted (only) to people with a gender different from their own. In general, LGBT stands as an umbrella term for non-cisgender and non-heterosexual people. Other acronyms are used to highlight other groups such as the intersex or asexual, but LGBT is still the most consensual form across organizations in Brazil.

\section{B. LGBT issues}

Transgender people are arguably the most vulnerable group, being Brazil the country where half of transgender women homicides in the world takes place [36]. Two famous brutal episodes involving travestis ${ }^{2}$ were the broadcast in Facebook of a video where Dandara was beaten to death by a group of guys in Fortaleza [16] and the shocking images of Veronica thrashed by policemen in São Paulo [35]. Such violence results in a life expectancy of around 35 years for transgender women [3].

Discrimination in form of bullying or moral harassment is also very common. A recent report shows that around only $19.3 \%$ feel safe in school [1]. Intolerance is not restricted to school, but also familiar environment such as in cases of home expelling or in employment market - $18 \%$ of companies in Brazil say they would put some resistance to hire gay people [33]. These facts help to explain the estimative that around $90 \%$ of transgender women are coerced into prostitution [30].

Institutionally, congressmen work (or attempts) has increasingly not matched the interests of LGBT population. Examples include the proposal of definition of family as the "union of a man and a woman" by the Federal law project (FLP) 6583/2013, the polemic religious lobby in the rejection of LGBTphobia criminalization by FLP 122/2001, the removal of the words "sexual orientation" and "gender identity" in the Ministry of Education guidance for schools curriculum in 2017 , or the nationwide proliferation of projects aiming to fight "gender ideology," such as the FLP 2731/2015 which tried to establish a prison sentence to teachers debating gender and sexuality in schools.

\section{Philosophical disclosure}

Scientific works are enclosed within a set of ontological and epistemological stances that describe the scientist regards

${ }^{2}$ Travesti is sometimes used as synonym of transgender woman, but the word historical use in latin American countries associated the former with lower income classes and marginalized areas. It is also sometimes used as a "third" gender, apart from male/female. The adoption of each term by women might highlight an embodied political stance. about how the world functions. The set of assumptions is commonly regarded as a paradigm. The conscious disclosure of a paradigm choice is what guides the practitioner throughout the decisions during the research process. Duarte and Baranauskas [13] point that the outline of the chosen paradigm may be useful to the academic community as a whole.

Our project stands upon the critical theory (or criticalideological) paradigm, as summarized by Ponterotto [29]. It regards reality as product of historical processes emerging from power relations. It also assumes that knowledge and perception of reality are subjective and mediated by values. The paradigm is summed up by the explicit directions of freedom, equality, and support for disenfranchised voices. Finally, it is intrinsic to the paradigm the will of changing the reality of socially oppressed groups. Therefore, values are taken into account as formative pieces of the scientific quest itself, not as qualitative biases.

\section{LITERATURE REVIEW ON SYSTEMS AND LGBT ISSUES}

In order to understand how Information and Communication Technologies (ICT) for LGBT people are created or evaluated by works in HCI, we conducted a systematic literature review by the following steps:

1. Search for a string of keywords ${ }^{3}$ in main digital libraries. The chosen ones were the ACM, Springer, and IEEE. We set the filters to consider only HCI publications from 2006 on.

2. We then removed: those which did not contain any of the search string terms string in the title, abstract, or keywords; duplicated papers; works-in-progress, conference, panel, or workshop calls, and posters.

3. Finally, we read the abstracts of the remaining publications and removed those which did not discuss the usage or design of ICTs by or for LGBT people.

\section{A. Results}

The review was first conducted in 2016, but we updated the results in May, 2017 in order to complete the overview in this paper. All presented results refer to the last one. Our first step resulted in 514 publications, cut down to 32 in the second one. Our final corpus consisted in 13 publications. The considered results are presented in Table 1.

\section{B. Analysis}

The first call for researches about LGBT people we found was in 2007, by Blodgett et al. [8]. In that work, the authors present a research agenda addressing avatar-based systems and their relation with identity construction and representation. Their assumption is that virtual worlds reproduce social structures that might narrow the experience of LGBT users, such as gender binary attribution and non-heterosexual marriages. One result was found in 2010 [25], but they began

\footnotetext{
${ }^{3}$ The keywords were intended to cover the LGBT umbrella in Portuguese and English, with terms like "gay,"

"transsexuality," "gender identity," as well as words related to the community work, such as "HCI" or "design".
} 
to appear in a constant pace after 2014. The subject has appeared in the last 4 years of the CHI conference. It also follows a surge of Queer Theory as a broad framework for
HCI in multiple contexts not restricted to LGBT people [e.g., $9,15,24,26]$.

\section{Authors}

Title

Blodgett et al. [8]

Kannabiran and Petersen [25]

Haimson et al. [21]

Homan et al. [23]

de Wiele and Tong [37]

Champagne et al. [10]

Deen et al. [11]

Haimson et al. [19]

Haimson et al. [20]

Blackwell et al. [7]

Yeo and Fung [38]

Beirl et al. [6]

Gonzales and Fritz [18]

Hardy and Lindtner [22] issues in virtual worlds
Lesbian, gay, bisexual and transgender (LGBT)

Politics at the interface: a Foucauldian power analysis

DDFSeeks same: sexual health-related language in online personal ads for men who have sex with men

Social structure and depression in TrevorSpace

Breaking boundaries: the uses \& gratifications of Grindr

Fuzziness in LGBT non-profit ICT use

Diversity through specificity: design lessons learned from the Games [4Diversity] Jams

Online Inspiration and Exploration for Identity Reinvention

Disclosure, Stress, and Support During Gender Transition on Facebook

LGBT Parents and Social Media: Advocacy, Privacy, and Disclosure during Shifting Social Movements

Relationships form so quickly that you won't cherish them: mobile dating apps and the culture of instantaneous relationships

GotYourBack: An Internet of Toilets for the Trans* Community

Prioritizing Flexibility and Intangibles: Medical Crowdfunding for Stigmatized Individuals

Constructing a Desiring User: Discourse, Rurality, and Design in Location-Based Social Networks
Publication venue

SIGMIS Database 38, 4 (2007)

NordiCHI (2010)

CHI (2014)

CSCW (2014)

UbiComp (2014)

ICTD (2015)

ACE (2015)

CHI (2015)

CSCW (2015)

CHI (2016)

\#SMSociety (2016)

CHI (2017)

CHI (2017)

CSCW (2017)

Table 1. Papers considered in the literature review 
Most of the analyzed papers focus on LGBT people as system users, with only two exceptions. Deen et al. [11] assess the impact of in-group sexual orientation diversity in design outcomes. Although it does not critically develop the context of LGBT people, they noticed that social critiques underlined the games designed by the participant groups. Beirl et al. [6] also describe the design of a new system, namely a mobile application to help transgender people to find a safe toilette, as part of a student design competition. The use of toilettes has been a hot topic on transgender issues, since it impacts a very basic, intimate, and natural need; transgender people are often not welcome in the toilette for people of the gender they identify with and do not feel comfortable in toilettes for people of the same sex attributed after birth. The system was conceived after ethnographies, interviews, and questionnaires with specialists and transgender people.

All other exemplars in the corpus present works on evaluation of systems. The analyzed system was chosen a priori for some authors, or resulted from the feedback given by research participants. Among a priori choices, Kannabiran and Petersen [25] were the only ones to explicitly present critical remarks in terms of social power relations, by analyzing how they take place in the interaction between transgender people and Facebook available mechanisms. Facebook was also chosen by Haimson et al. [20] to assess transgender people use experience during gender transitioning. Gender transitioning is another important subject on transgender issues and corresponds to the period where transgender people adapt their identity expression to accommodate the gender they identify with. It might involve body, style, and name, among other changes. The paper investigates how the use of Facebook might be associated with stress and support during gender disclosure.

Most popular systems for evaluation were location-based applications for gay and bisexual men [22, 37, 38], which offer means for users to chat with other users nearby. They adopt different approaches for users to reach others and means of interaction provided. For instance, Hornet displays a list of profile pictures ordered by distance and offers instantaneous chat, while Tinder only allows users to chat after they show mutual interest on each other by "liking" or "disliking" profiles. While Grindr just allow one free picture to be displayed, other networks such as Scruff allows users to upload multiple. Pokes, likes, and other forms of interaction are also differently available across the apps.

Hardy and Lindtner [22] analyze the relations between discourses and design choices of location-based applications and rural users. They discuss the construction of the universal gay user based on urban experience and how rural users appropriate and negotiate the means of interaction during their experience of use. De Wiele and Tonga [37] study the "uses and gratifications" for Grindr users and also analyze the use in urban and rural areas, as well as the use of Grindr for selfdisclosure of information. They point out that the motivations for use of Grindr is not exclusively related to sex and the conversations and disclosures made in the app reflect such gratifications. Finally, Yeo and Fung [38] present an inquiry on how the interface design and affordances of location-based applications affect the construction of long-term relationships. They argue that the foreground of profile pictures in respect to textual descriptions privilege physical appearance and casual hook-ups.

A crowdfunding website, YouCaring.com, for transgender men was analyzed by Gonzales and Fritz [18]. They discuss the flexibility of privacy mechanisms to control the exposition of shared information and the presence of intangibles, such as emotional support and political values, and how they affect the use of systems by vulnerable populations. Homan et al. [23] investigated the structure of TrevorSpace social graph a social media for LGBT youth, and the presence of depression, finding a correlation between the depth of involvement of users in the network and the illness. Haimson et al. [21] analyze sexual health-related language in Craigslist, a U.S.American advertisements tool, and its relation with HIV rates in a certain location.

Haimson et al. [19] investigated the online aspect of style change by transgender people. They argue for the consideration of finding inspiration and getting advice from strangers, as well as experimenting with close friends when designing a social media that accommodates identity presentation. The use of ICT in non-profit LGBT organizations is visited by Champagne et al. [10], who discuss issues raised by the blurring of boundaries between professional and personal interactions on Health House, a nonprofit organization for gay men and black transgender women. Finally, Blackwell et al. [7] consider the use of social media by LGBT parents. The paper points out that LGBT parents use social media to detect unfriendly and friendly people in the network and discusses the importance of privacy mechanisms and how such users become "incidental advocates," by having their posts regarded as advocacies even if it was not their intention.

As a subject that has recently begun to occupy $\mathrm{HCI}$ agenda, there are naturally several opportunities for works about LGBT people. This literature review can also be further updated including works yet to be indexed by digital libraries, such as Pereira and Baranauskas [28], which make a critical survey about how LGBTphobia might be reproduced in social media interaction mechanisms, or works published in correlated areas or which place LGBT issues in a more peripheral place in the investigation. In particular, this review was sufficient to point a gap in the HCI exploration of designing apps: despite several design recommendations, we found just two works who actually tried to materialize them into a new product. The presence of LGBT people in the design process is also hardly explored, as well as an explicitly critical approach on works to help build a more equalitarian society.

\section{MobILE APPLICATIONS AND THE LGBT ISSUES}

We also conducted a review with the goal of finding how support for LGBT people is currently provided by mobile applications. The first survey was conducted in May, 2016, but we repeated the process in May, 2017 to update our 
findings. Initially, we executed a search on Google's App Store for the terms LGBT, lesbian, gay, bisexual, and transgender. We then analyzed those in English or Portuguese and fit them into broad categories related to how they might fight against LGBTphobia.

We also made an exploratory search for terms describing forms of violence such as harassment or transphobia to seek forms of combatting prejudice in other contexts that did not appear in the first approach. In this case, we only considered apps that explicitly stated they aimed for support of LGBT people.

\section{A. Results}

We categorized the results from the surveys in 9 groups: social, sexual, games, streaming, press, geographic guides, static content portals, mobile themes, and health support. All results are from the searches made in 2017.

The first category is comprised of social networks apps. The most prominent example is location-based dating apps, which we previously discussed. Only one dating app directed to women, called Spicy, reached the mark of 1 million (or more) downloads, while Grindr, the most popular application for men, surpassed 10 million downloads. Other apps for men, such as Hornet, Scruff, and Blued, have reached at least 1 million downloads. The top applications in terms of downloads, however, do not restrict the gender allowed to join the network, such as Tinder, which surpassed 100 million downloads. The results for men also include more apps directed towards more specific niches, such as bears and daddies. Some apps include other features from social media, such as posting and creation of groups, but the chat with other people is arguably the predominant feature across this corpus. Exceptions are also made by online forums, such as Grasshopper Mob, with 500-1,000 downloads, which intends to provide a place for LGBT people to discuss important subjects.

The "sexual" category encompasses Kamasutra guides and sexual toys, such as an app that allows user to control vibrations from the smartphone. The "games" category is selfexplained. The next one, streaming, includes apps that offer digital audiovisual content, such as radio or TV stations - for instance, the LGBT Gay Music Radio Stations app broadcasts over 30 "LGBT \& gay" radio stations around the world. The press category is similar to the previous, and includes digital magazines or newspapers, such as Frock, a digital magazine focused on transgender people and drag queens.

In geographic guides, we included applications directed to travelers, such as the Bump! series, as well as recommendation/alerting applications such as Espaço Livre, which will be further discussed. Under static content portals, there are information portals and blogs, such as Stigmabase, as well as apps related to conferences on LGBT issues. The "mobile themes" category contains applications to customize the cellphone visual interface or pictures with images related to LGBT pride, such as the rainbow flag or transgender icons. Finally, the health support apps offer varied services to physical health, such as calendars to control hormonal injections and voice exercisers.
We considered 193 mobile apps for the search for "LGBT," 222 for "lesbian," 223 for "gay," 208 for "bisexual," and 198 for "transgender." In all of them, the social category was the biggest, accounting for more than $50 \%$ of apps for "lesbian" (111), "gay" (147), and "bisexual" (114). For "transgender," 75 results were found. The other most popular categories for "LGBT" were static portals, mobile theme, streaming, and geographic guides - respectively, 20\% (39), $16 \%(31), 14 \%$ (27), and $10 \%$ (19); for "lesbian," geographic guides and static portals - respectively, $20 \%$ (44) and $15 \%$ (34); for "gay", geographic guides, which contemplated $14 \%$ (31) of the results; for "bisexual," games and static portals $17 \%$ (36) and 13\% (28); and for transgender, static portals and games - $21 \%(41)$ and $15 \%$ (29), respectively. The other categories did not reach $10 \%$ of results in each term. Remarkably, health support apps were only identified in searches for bisexual and transgender and sexual apps only for gay and lesbian (just one, in the latter). Figure 1 depicts the number of apps for each category according to the searched term.

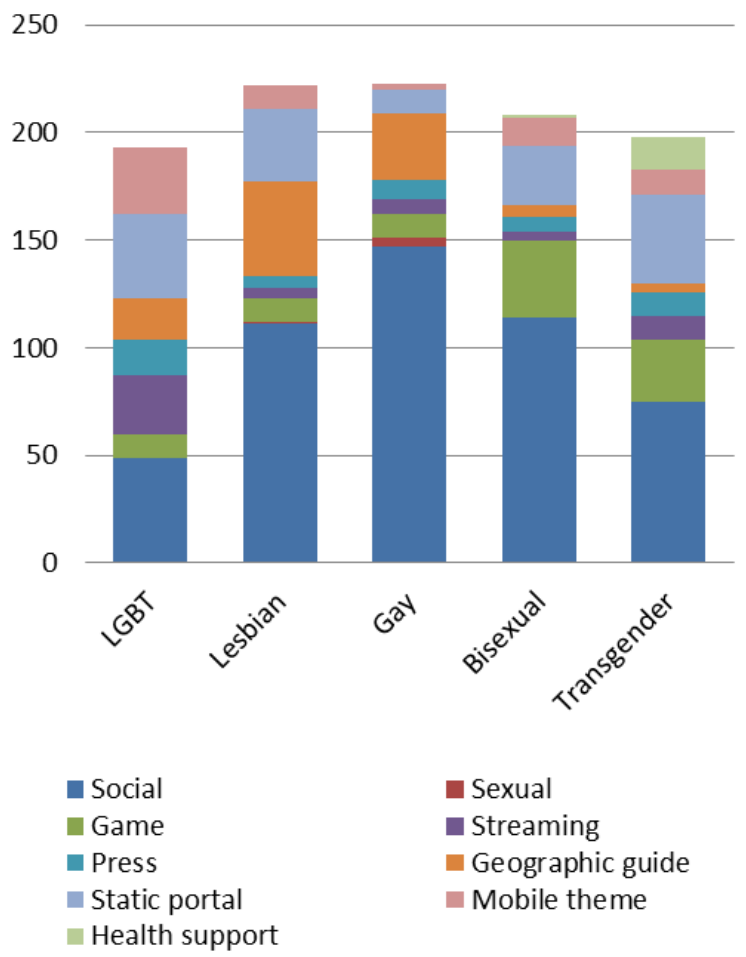

Figure 1. Presence of each category of apps in results for searched terms.

From the violence-related terms search, we considered 5 more apps. They fit on the previously defined category: 2 social, 1 static portal, 1 game, and 2 geographic guides. We also searched for the terms queer, asexual and intersex, but no new app was presented.

\section{B. Analysis}

It is not trivial to design applications with a critical goal, since the meanings produced by interaction might lead to other directions. This was more evident when analyzing the games 
category. For instance, one might wonder if it is possible to design a quiz to detect one's sexual orientation, such as the multiple Gay or Straight tests, or to detected prejudiced opinions, such as the Homophobia Test, without reinforcing prejudiced judgements or oversimplifying complex facts. Other apps such as My Virtual Gay Boyfriend, where user customizes an avatar of a gay boy, or Qutie Life, where user runs a city that grows according to the success of its pride parades, might also arguably recur to stereotypes about LGBT people. The same sort of generalization can be found in streaming apps, since a rigid definition of "LGBT content" is inconceivable. The "bubble effect", i.e., the isolation of people inside clusters of like-minded acquaintances is also a possible consequence of networks targeting a very specific audience.

Furthermore, most of the apps do not explicitly consider a critical goal. Their interaction design also may not match this possibility [eg. 38]. Table 2 presents some apps self-stated as fighting prejudice and their approach to the subject.

\begin{tabular}{|c|c|}
\hline App name & Description \\
\hline Binder Reminder & $\begin{array}{l}\text { Helps people in process of body } \\
\text { masculinization to monitor the } \\
\text { use of chest binders. }\end{array}$ \\
\hline Bullied Buddies & Network for victims of bullying. \\
\hline Espaço Livre & $\begin{array}{l}\text { Places markers in a map to show } \\
\text { where episodes of homophobia } \\
\text { happened in Brazil. }\end{array}$ \\
\hline Hate Crime & $\begin{array}{l}\text { Portal with laws and regulations } \\
\text { about hate crimes in the U.S. }\end{array}$ \\
\hline Homophobia Test & $\begin{array}{l}\text { Trivia game to detect homophobe } \\
\text { people by their answers. }\end{array}$ \\
\hline Refuge Restrooms & $\begin{array}{l}\text { Geographically display the } \\
\text { location of safe bathrooms for } \\
\text { transgender people. }\end{array}$ \\
\hline Xomnet Security Buzz & $\begin{array}{l}\text { A button that makes noise to alert } \\
\text { surrounding people about an } \\
\text { ongoing harassment. }\end{array}$ \\
\hline
\end{tabular}

Table 2. Examples of self-disclosed LGBT support apps.

From the results of the review, we list below some identified means through which mobile applications currently (or could potentially) address the fight against LGBTphobia:

\section{1) Engagement in communities or creation of social ties}

Social change can only take place through group mobilization. Leaders praised for revolutionary contributions have only achieved them after inspiring and engaging communities around a strategy or a cause. Collective reasoning is a pillar of modern democracy. Outside the political realm, sociability is also a desired feature for individuals. Philosophers and social scientists have extensively explored the notion of alterity and the dialectic construction of the "self" after the "other". Being part of social relations affects our self-esteem, emotions, and our personal growth.
Association with people is also important for LGBT people to build their identity. It provides inspirational figures, relieves loneliness by showing that other people face the same situations as one does, and creates a protection feeling that allows one's own voice to be uttered. However, we have already discussed some findings by studies suggesting a negative impact of dating apps on these aspects. Although sex is an important element of human experience, there is a lack of exploitation of other social elements in the currently available applications, contributing to (or, at some extension, because of) Facebook dominance on social binding.

2) Rise of awareness and alterity creation through story sharing, news, and informational content

To be able to read stories from other people is also an associative feature. It allows people to comprehend a certain time and a certain space, to know what people had been through, to know places to avoid or to go to, to create a political consciousness around the state of rights and what it ideally should be. Similarly, informative content also supports the awareness of current challenges, fights, and progresses; it gives one confidence to demanding their rights and knowledge about legal boundaries and protections.

\section{3) De-stigmatization of sexual activities}

LGBT people were persecuted during centuries and are deprived from fully living their gendered and sexual experience in many parts of the world. In this sense, the exposition to LGBT-related content might lessen the feeling of being a "deviant" or "incorrect" behavior. Apps from the "sexual" category might support LGBT people through education around practices which related material is, traditionally, predominantly on cisgender and heterosexual experiences.

\section{4) Self-disclosure and strengthening of self-pride}

Most mobile themes applications build on the idea of "pride." The use of filters in photos to be later shared might create an associative impact, such as the use of badges and profile decorations on Facebook pictures. Individually, assuming one's own sexuality and gender identity might improve confidence, feeling of belonging, and self-acceptance.

\section{5) Health monitoring}

There are some health concerns that might affect LGBT people in a larger or specific proportion. When searching for "bisexual," only one application, related to tracking of periods, was found. All other results were found under "transgender," and are related to specific experiences of this population. The apps included calendar to control the use of chest binders by transgender men undergone through mastectomy surgeries and voice exercisers for people to adapt their voice tones to what is socially expected for the gender they identify with. 


\section{6) Call for help}

In face of emergencies or life-threatening situations, applications in this category help people to ask for help using panic buttons or sending pre-configured messages.

\section{A SEMIOPARTICIPATORY APPROACH TO CRITICAL CODESIGN}

Codesign grounds its philosophical stance in Organizational Semiotics (OS). In OS theory, an organization is said to consist of 3 different layers or information systems (IS) [27]: a broad informal one, made of beliefs, intentions, commitments, and habits; a formal one, defined by bureaucracy and rules; and a technical one, comprising the technological artifacts themselves. They are best represented by the image of the "semiotic onion," presented in Figure 2.

Codesign is based on the realization of workshops, meetings where the most interested parties in the problem domain engage in activities with artifacts and techniques from PD and OS. The intent of the workshops is to carry knowledge from each external layer and embed it into a meaningful product, which will then produce a new effect back to society. This rationale, known as Socially Aware Computing (SAC) [5], is represented at Figure 2.

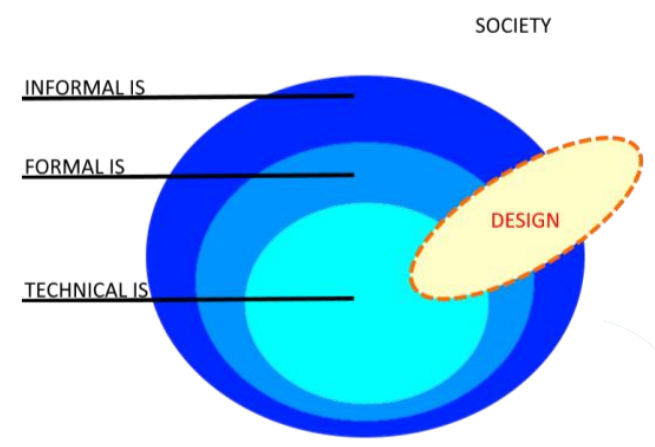

Figure 2. Representation of the semiotic onion and the inscription of design activities in SAC

\section{A. Participants}

The contact of volunteers began after the study approval by the Committee of Ethics in Research ${ }^{4}$. We reached candidates by posting in Facebook LGBT groups and our personal timelines and stimulating the broadcast to people interested in activism or social work. We intended to have a balanced representation of different gender identities and sexual orientations while keeping a number of volunteers suitable for the participatory activities. We also restricted the participation to people older than 18 years and living in Campinas, São Paulo. Our final group, including the researchers, had 24 people: 3 queers ${ }^{5}$ (1 bisexual, 1 pansexual

\section{${ }^{4}$ Certificate of Presentation for Ethical Consideration:} 58185916.3.0000.5404.

${ }^{5}$ Queer is an umbrella term for people whose gender lived experience does not fit in the male/female binary, but also does not necessarily feel part of the transgender label. and 1 homosexual $^{6}$ ), 1 homosexual transgender man, 2 transgender women or travesti ( 1 heterosexual and 1 bisexual), 5 cisgender heterosexual women, 2 cisgender heterosexual men, 4 cisgender bisexual women, 2 cisgender bisexual men, 1 cisgender lesbian, and 4 cisgender gay men.

\section{B. Methodology}

We divided our codesign activities into two major groups: organization and context and codesign workshops. The former intended to clear up the problem domain, i.e., to know more about issues related to the group and use of existent applications. We will discuss it in details in the next section. The latter corresponds to the (co)design cycle and was subdivided in 3 steps: pre-design or requirements elicitation; design or product conceptualization and prototyping; and postdesign or evaluation. Volunteers were asked to give a name to each one, in order to homage LGBT representative people. The activities and artifacts used are listed in Table 3. Workshops were realized between November, 2016 and November, 2017.

\begin{tabular}{cll}
\multicolumn{1}{c}{ Phase } & Workshop name & \multicolumn{1}{c}{ Methods and tools } \\
\hline $\begin{array}{c}\text { Organization } \\
\text { and context }\end{array}$ & Alan Turing & $\begin{array}{l}\text { Storytelling; picture } \\
\text { cards }\end{array}$ \\
& David Bowie & Exploration test \\
\hline \multirow{2}{*}{ Ellen Page } & $\begin{array}{l}\text { Stakeholders diagram; } \\
\text { evaluation frame }\end{array}$ \\
& Dandara & $\begin{array}{l}\text { Brainwriting; } \\
\text { braindrawing }\end{array}$ \\
& Cássia Eller & $\begin{array}{l}\text { Prototype evaluation } \\
\text { Discussion }\end{array}$ \\
& Laerte & $\begin{array}{l}\text { Evaluation of building } \\
\text { blocks of culture }\end{array}$ \\
& Freddie Mercury &
\end{tabular}

Table 3. Methods and tools used in each workshop.

In order to foster participation and ease the start of activities, each workshop besides the first was preceded by an online "warm-up" task. The tasks consisted in short questions, to be answered either in Google Forms or in the discussion platform Consider.It, intended to link the discussion from a previous workshop to the practices put in place in the next one.

\section{ORGANIZATION AND CONTEXT WORKSHOPS}

For the first workshop, we would like to begin the creation a comfortable and trusty relationship with the volunteers. 7 selected volunteers went to the meeting. We began it by lecturing an overview of the research and exposing our intended outcomes. They were asked to sign an Informed

${ }^{6}$ Personal identification and social interpretation of a gendered body are two interweaving aspects of someone selfdisclosure. In this particular context, the volunteer claims the unsuitability of gender labels, but is socially seen as a man, which reflects his description as an homosexual, here referring to an exclusive attraction for men. 
Consent and we encouraged them to correct us if we say something offensive. This process was repeated every workshop someone new attended.

\section{A. Workshop 1: Alan Turing}

The first workshop was baptized after Alan Turing, the highly influential British scientist who inaugurated studies in a vast range of Computer Science fields and committed suicide in 1954 after convicted to chemical castration for homosexuality.

For the main activity, we spread 50 cards on a table. Each card belonged to one of the following categories: politics, quotidian, places, occasions, society, emotions, or news. There were 20 news cards and 30 cards equally distributed among the other categories. The former contained only a headline related to LGBT or politics and the others an icon representative of some aspect of the category, as depicted in Figure 3 . We chose to include politics in order to foreground formal aspects of the context.

Each volunteer was then asked to randomly pick a news card and any other one. Then, we invited them to link the cards to two stories - a positive and a negative one permeated by one of the following themes: activism, politics, or LGBT. Even though the stories could be fictional, all participants told a real story. They are summarized in Table 4.

Finally, we proposed a discussion about how technology could be used to give an alternative path for the negative stories, if possible, linking it with public policies creation. 4 ideas were proposed: (a) Facebook as a popular and addictive source of information, where it is possible to create mutual support groups; (b) a game where children can engage in activities from all forms of gender stereotypes in order to show that there is no inherent link between the tasks and the gender; (c) a reporter of LGBTphobia episodes and mediation of solidarity; (d) a system that finds favorable legislators and judges to provide assistance and orientation in specific cases.
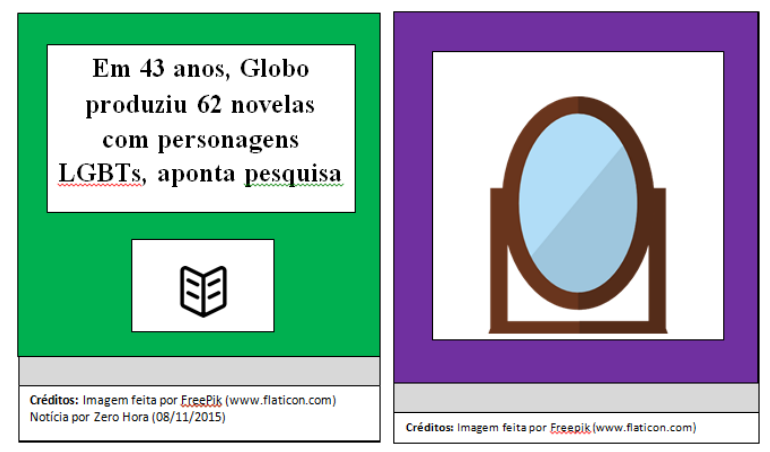

Figure 3. A headline from Zero Hora (November, 2015), stating that 62 Globo $^{7}$ soap-operas have portrayed LGBT characters, and a mirror. Respectively, they represent news and quotidian categories.

Participants reported they did not know about any application with similar features to those suggested. Support, education, complaint, and guidance can be seen as the

\footnotetext{
${ }^{7}$ Globo is the major Brazilian soap-opera creator for TV.
}

underlying themes of the proposals. Participants pointed out that Facebook is also a channel to broadcast of hateful content and lacks proper interaction tools to fruitful debates. Also, an educational tool must take into account the barriers imposed by society to genderless life and the negotiation everyone must engage with in order to belong to a group. Moreover, a way of preventing unprepared or malicious people of getting involved in cases of discrimination or aggression is fundamental. Finally, the generation of statistics might be helpful to fill in the lack of official reports.

\section{B. Workshop 2: David Bowie}

Based on the previous activity, we wanted to further discuss the use of geolocation, suggested in proposals (c) and (d). We made the following affirmation on ConsiderIt and asked the volunteers to give an opinion as a warm-up for the workshop: "The use of geolocation can be an important resource for applications fighting intolerance against LGBT people." 14 people participated, 12 favorably and 2 opposing the affirmation. We present next the top arguments:

- In favor: it might be useful to call engaged people for help in emergency cases, as a panic button, or to find help from solidary people. It facilitates the choice of safe places to go, as well as the avoidance of dangerous ones; it is an embedded feature in most smartphones; it allows the creation of a map of violence and the further use to report statistics; it helps the creation of a network among LGBT people.

- Against: it might create a target in places marked as friendly and create a segregationist bubble effect; geolocation is sensitive information and prone to fraud.

In the workshop, we invited the volunteers to split into 2 groups and navigate in two systems: the Brazilian Chamber of Deputies $^{8}$ website and the app Espaço Livre. We chose both to assess, respectively, the search for legislative information and the use of geolocation. For the former, we invited volunteers to search 2 proposals favorable to LGBT people and for Espaço Livre, to navigate in the map the app displays, making notes about the decisions and impressions they had. 7 participants were present and the workshop was named David Bowie, in homage to the British gender-bender musician, performer, and pop icon, deceased in the beginning of 2016. 
P1 Researches that present an informed consent, since transgender people are a particularly vulnerable group, often exploited for the sake of the practitioner's career.

P2 A love story about two men who faced adversities to be with each other after falling in love in a Catholic seminary.

P3 Small groups have organized to help women facing harassment or abuse.

P4 Presence of inclusive churches that accommodate LGBT people.

P5 Facebook groups that help people to bond with others with similar struggles, although it is a hostile place.

P6 LGBT people have been increasingly elected, showing that representativeness has not ceased to grow.

P7 Barack Obama awarded Ellen DeGeneres with the Medal of Freedom.
The headline from Figure 2 might be a misleading clickbait, because it does not say anything qualitative about the characters representation.

Schools as places of many moral, social, and physical aggressions to LGBT people, even by teachers.

A radio headline saying that rape of women in the city has increased. Laws are often targeted to treat the problem after it happened, instead of preventing it.

A guy was expelled from home by his priest father for being gay.

A girl developed panic crisis after receiving death threats and having her bedroom wrecked by her mother, for being lesbian. Today they talk to each other without mentioning personal relationships.

An 11 years old boy said he had "lost his reference of masculinity" after his father said he was dating another man.

Dialogue has been giving place worldwide to rivalry between poles, as in Mr. Trump's election.

Table 4. Summary of stories shared on Alan Turing workshop.

In the Chamber of Deputies website, each group adopted a different approach: one chose to search directly for parties and law projects they knew were favorable, while the other searched for keywords related to LGBT and then explored the news in the result page. None of them had previously used the website, being habituated to get informed via Facebook posts. They mentioned that it is hard to quickly identify favorable projects, because examples are presented mixed, the language is too technical, and news are too short. Also, they feel a disconnection between the laws being voted and the violence episodes. Such results have already been pointed out [e.g., see 14 or 32]. However, participants suggested that would be important to follow the laws proposals, if an aid to interpret the results was given.

As for Espaço Livre, participants complimented the ease of use, but pointed out the lack of details and reuse of information. They mentioned the fact that the buttons collect two different kinds of violence, but the map exhibits only one color of marker (see Figure 4). It also does not collect further information about the episode to inform users neither allows them to assess the reports. Participants also suggested features of warning users nearby risky areas, offering help, and messages communication. Such remarks resemble the use of technology as builder of a support network proposed in the first workshop. They also mentioned the navigation app Waze as an example of tool to collectively assess reports and moderate content.
The importance of accessing public regulation and the suitability of Waze's collaborative audit tool were subjects of the second warm-up. Considering apps directed to collect stories or reports, participants stressed the importance of having a way of auditing information to not drive people to fake safe places - it would be necessary to have a clear policy of use, a tutorial that contextualizes the functionalities, details about the occurrence and possibility of anonymity and edition. Another raised concern is the prevention of "trolls," which might perform fake validations or report fake incidents with malicious purposes. The access to legal information was said to be helpful to bring confidence in dealing with discrimination, and it would be good to have a place where it can be easily found. A new app, TODXS, launched in May, 2017, tries to fill in this gap.

However, volunteers mentioned it would be palliative, since it does not replace educational campaigns. Additionally, it demands a dedicated team to translate the technical language and keep it updated, especially because Brazilian portals often do not provide machine-readable information, as demanded by law [2]. 


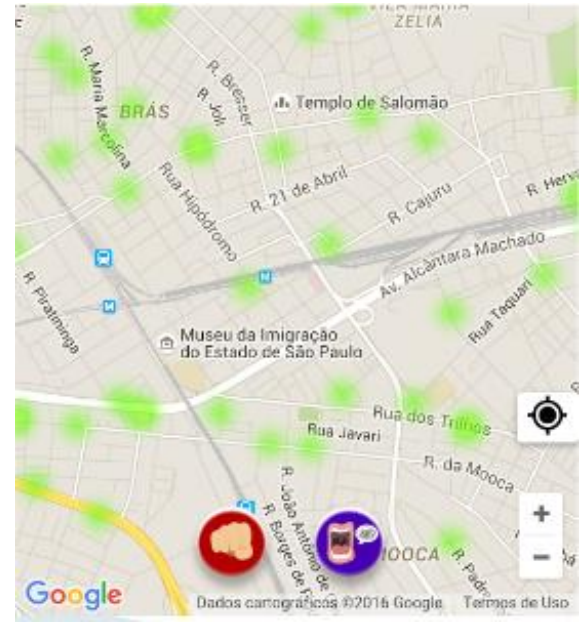

Figure 4. Screenshot from Espaço Livre - users are provided with 2 buttons, to report physical or verbal aggression. The complaint is then added as a green spot in the map.

\section{CODESIGN WORKSHOPS}

The third workshop marked a transition from the organization and context to codesign phase. We used two artifacts, the stakeholders diagram and the evaluation frame, to, respectively, list interested parties and their respective issues in the context of LGBT discrimination and ways to prevent and fight it. It provided us with a list of requirements to a possible application, though we still had not defined what this application would be. It was named after Ellen Page, a young Canadian lesbian actress and activist.

The application gained some form in the following workshop, named after Dandara dos Santos, the Brazilian travesti beaten to death in Fortaleza. In this workshop, we firstly conducted a brainwriting activity, where participants sat in a circle and wrote on a paper features or requirements about an app based on the previous discussions. After 1 minute, the paper should be given to the person beside, who had 1 minute to read the first idea proposed and comment it. The activity stopped when each paper reached back its first owner. Later, a similar activity was made, but this time participants should complete the draw of an application begun by others, in a braindrawing activity. The workshop was preceded by a warm-up on the offer of help by users to other users inside the application. It inaugurated a discussion around the ability and intentionality of possible helpers, which was carried through the following activities.

The fifth workshop featured a warm-up intended to preevaluate the application prototype. It contained a form where the application main features and characteristics were listed and volunteers assessed whether they were appropriate by using a Likert scale. Cássia Eller, a popular bisexual Brazilian singer, was honored by the workshop name. In this workshop, we debated the functionalities raised by the previous activities and evaluated a functional digital prototype based on the consolidation of braindrawing results.
Next workshop, Laerte, hosted a discussion about some sensitive open issues about malicious people exploiting the application. In this workshop, the registration, content moderation, and ask for help processes were defined. The application name, LGBTrust, was also suggested in this activity. It was not preceded by a warm-up activity.

Prior to last workshop, an evaluation of simplicity according to John Maeda's laws of simplicity was conducted with HCI experts. The final workshop, named Freddie Mercury, was dedicated to an evaluation of the adoption of SAC in the research, in order to assess whether participants' voices were indeed heard and embedded in the product. It was based on Edward Hall's theory of building blocks of culture.

The main goal of the app is the protection of users through the articulation of educational, protective, and social aspects on a network of supportive and engaged users. In order to sign up in the application, one must be either a verified partner or be invited by a registered user, as per the decision in Laerte workshop. It contains five main features, described below. A screenshot of some screens can be seen in Figure 5.

- Panic button: a button which, when pressed, sends a predefined call for help to people nearby or selected contacts, depending on user configuration. Initially, the button was conceived to send alerts to police, as well. However, since it depends on the availability of corresponding systems in the police side, it was replaced by just opening the dial screen with the police number typed (if user chooses to call the police). The position of the caller is displayed on the map and updated as long as the call is on.

- Support: a place where people can state possible ways of helping other, as well as ask for help. After Laerte workshop, it was decided that people would be able to reach only trusted partners directly, in order to avoid unprepared or malicious helpers. However, the final evaluations pointed out that a form of help for not so sensitive issues should also be available. Volunteers also suggested the use of artificial intelligence techniques to provide guidance in simpler issues.

- Share of experiences: creation of three types of content stories, mobilizations, and reports. The former is related to personal experiences, the second, to collective events (such as crowdfunding, protests, or parties), and the latter, to the indication of places where episodes of prejudice or violence happened. All of them feature a textual description. They are displayed on a map (the landing page) and in a timeline. The group was not consensual over the term "mobilization," since it might be associated to explicitly political actions. All content can be reported in case they are offensive or hateful. The number of reports and the reason are displayed with each post.

- Information: educational material about gender and sexuality, laws, news, among others.

- Advertisement: registered partners can advertise services related to LGBT issues. 


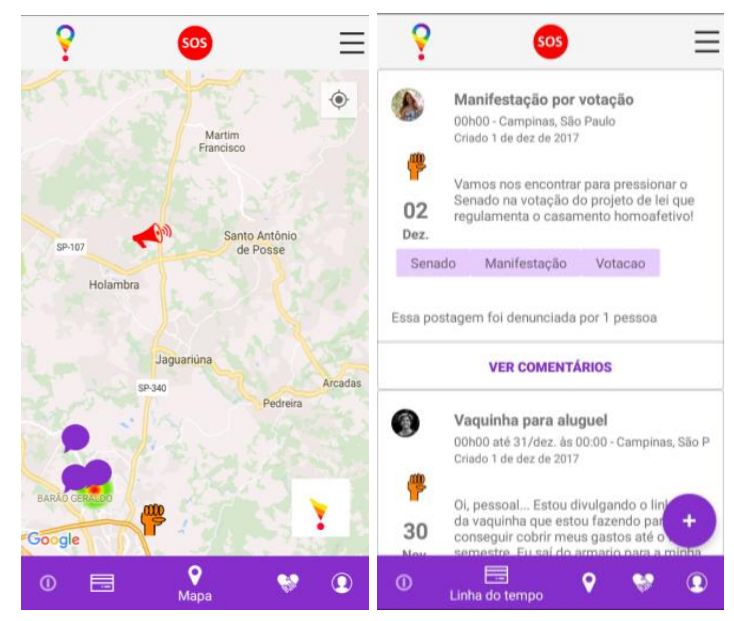

Figure 5. Screenshots of LGBTrust map and timeline pages

Some of the means of fighting against LGBTphobia we previously discussed are evident on the application. Firstly, the explicit protective features include the panic button and the "ask for help" feature. The information portal corresponds to the most educational part. Finally, the share of experiences establishes the social aspect of the application.

\section{VIII.DISCUSSION}

The codesign cycle we described has no intention of revealing a universal truth about LGBT demands or how to supply them. It must be noted that the methodology is an attempt to build an application upon participatory knowledge (co)construction - its expected outcome is a better contextualized app, not an undeniable solution to social problems. However, through it we were able to identify problems and silver linings of LGBT reality from sociological personal backgrounds to technical experience with applications. Moreover, the proposed activities resulted in a functional prototype with features both distinctive from the current corpus and meaningful to concerns raised by interested parties. Hence, we believe this experience helped to validate codesign not as the definitive method, but as a well-suited approach to critical socially aware design.

We were also able to identify concerns and requirements when dealing with applications directed to LGBT people. Content moderation and concerns with privacy are a central issue, as already pointed out by previous works. We contextualize these concerns in LGBTrust, departing from interested people's personal experience and their own perspective on how a system could accommodate it. Prejudice faced day-by-day is also transported to online interaction, what makes necessary for information systems to stand for a moral ground, namely the respect and tolerance for diversity. Although some apps offer functionalities to give voice to people, it is important for users to know if this voice is being heard and how, including in the research process. There is a form of political participation demand that requires a skilled and engaged group to mediate the access to information, as some previous works have pointed - the specific use of public data for awareness of disenfranchised people, however, seems a potential subject to be explored.

There are two main differences of LGBTrust in relation to the existing corpus. One is the explicit consideration of privacy and safety issues. Volunteers opted for an invitationbased registration process, in order to create a safe and comfortable environment. The geolocated posts contain a description, in order to offer more details around the stories, according to what was discussed about the Espaço Livre app. Posts can also be created anonymously, in an attempt of stimulating users to share personal experiences. The moderation process was also privileged throughout discussions in all workshops. Although the contact with supporting institutions is provided by other applications, it is usually based on the availability of phone numbers and emails, but not direct requests. Moreover, the limitation of some requests to trusted partners is intended to prevent malicious individuals from exploiting people in sensible situations.

The other difference is related to the articulation of all these aspects. Through the descriptions on shared content, we target the social benefits of alterity and empathy. It also generates an educational aspect, through the information not only by traditional media outlets, but also with regular people. It is also linked to protection and creation of groups, but in a way that does not privilege only the sexual aspect of interactions. It also has an impact on the awareness of the surrounding environment through the description of reports. The content of publications might also spontaneously trigger destigmatization of sexual practices and self-pride if these subjects appear on-the-fly. The contact with registered partners is also inherently a social feature and also a source of information.

PD is traditionally associated with specific contexts, such as shared workplaces. In our case, the only shared background was the city where participants live and the goal of fighting against LGBTphobia, which might partially explain the small quantity of people participating in the workshops. It might seem a lack of engagement, but the online participation in warm-ups, the formation of a small group, which attended most workshops, the contact between researcher and participants about the work in between workshops, and the almost constant presence of at least one person going for the first time suggest the opposite. The willingness to talk about the subject is also reflected in the sharing of only real stories during the presented activities. This process also reflected the effect of variety in features in the app that seem applicable to other vulnerable groups, since volunteers' experience also interlaced with other groups besides the LGBT. Being reality apprehensible only through personal interpretations according to Semiotics tradition, it is likely that activities with other people result in new knowledge to be added.

The states of technique and art reviews illustrate some opportunities to research. Firstly, the apps stores enclose a vast corpus of knowledge interpretable by a critical read on how the results for a term and the social views about it dialectically relate to each other, perhaps throughout a timeline. Such contextualization might provide scientists with rich 
sociological data to better understand the technical productions around LGBT people. It must be stressed, however, that mobile applications are not the only technological artifact that can be used and this review does not account for a general state of technique around LGBT issues.

Also, each result or category might be seen as a source of investigation. As we described, HCI works are dominated by mobile location-based apps, but there is a wide range of other categories that might be evaluated - especially those targeted at improving people's lives - as well as other LGBT particular contexts of use. In particular, lesbian and bisexual women and non-U.S. citizens are extremely underrepresented in studies about the LGBT spectrum, but there is also room for new takes on support of disenfranchised people by focusing on different goals (e.g., other unexplored ways of support), groups (e.g., other categories, places, economic conditions), technologies (e.g., the Internet of Things), or design and evaluation methods.

\section{CONCLUSION}

LGBT people face a range of daily struggles. Few mobile applications have been developed with the explicit goal of supporting them and HCI still lacks both evaluation and design works on the issue. In this paper, we presented a systematic review on the state of art and technique around LGBT issues in HCI and mobile application production. It the experience of a critical codesign methodology to this end, focusing in the lessons learned in the workshops. Some problems with existent applications were suggested, as well as potential paths to be refined or explored. Finally, we briefly describe a new application (co)conceptualized with a sexually and gender diverse group and link it to experiences raised during the workshops.

\section{ACKNOWLEDGMENTS}

This work is funded by CNPq, \#308618/2014-9, CNPq, \#132272/2016-4, and FAPESP, \#\#2015/16528-0. We thank UNICAMP Center of Informatics Applied to Education (NIED) for providing material and place for the workshops, the colleagues from InterHAD group, and the study volunteers. Freepik is the author of the icons used in the presented cards, taken from FlatIcon.com.

\section{REFERENCES}

[1] ABGLT (Associação Brasileira de Lésbicas, Gays, Bissexuais, Travestis e Transexuais). 2016. Pesquisa nacional sobre o ambiente educacional no Brasil 2016: As experiências de adolescentes e jovens lésbicas, gays, bissexuais, travestis e transexuais em nossos ambientes educacionais. Retrieved May, 2017 from https://goo.gl/8AU3eB.

[2] Pierre Andrews; Flávio S. C. da Silva. 2013. Using Parliamentary Open Data to Improve Participation. In Proceedings of the 7th International Conference on Theory and Practice of Electronic Governance, 242-249.

[3] Pedro P. S. Antunes. 2010. Travestis envelhecem?. MSc Dissertation. Pontifícia Universidade Católica de São Paulo, São Paulo, SP.

[4] Simone de Beauvoir. 1986. Le deuxième sex. Gallimard Education.

[5] M. Cecilia C. Baranauskas; M. Cecilia Martins; José A. Valente. 2013. Codesign de redes digitais. Penso.

[6] Diana Beirl; Anya Zeitlin; Jerald Chan; Kai I. A. Loh; Xiaodi Zhong. 2017. GotYourBack: An Internet of Toilets for the Trans*
Community. In Proceedings of the 2017 CHI Conference Extended Abstracts on Human Factors in Computing Systems, 39-45.

[7] Lindsay Blackwell; Jean Hardy; Tawfiq Ammari; Tiffany Veinot; Cliff Lampe; Sarita Schoenebeck. 2016. LGBT Parents and Social Media: Advocacy, Privacy, and Disclosure during Shifting Social Movements. In Proceedings of the 2016 CHI Conference on Human Factors in Computing Systems, 610-622.

[8] Bridget M. Blodgett; Heng Xu; Eileen M. Trauth. 2007. Lesbian, gay, bisexual and transgender (LGBT) issues in virtual worlds. SIGMIS Database 38, 4: 97-99.

[9] Samantha Breslin; Bimlesh Wadhwa. 2014. Exploring Nuanced Gender Perspectives within the HCI Community. In Proceedings of the India HCI 2014 Conference on Human Computer Interaction, 45-54.

[10] Ryan Champagne; Julio Guerra; Chun-Hua Tsai; Jocelyn Monahan; Rosta Farzan. 2015. Fuzziness in LGBT non-profit ICT use. In Proceedings of the Seventh International Conference on Information and Communication Technologies and Development. Article no. 30.

[11] Menno Deen; Frank Nack; Mata Haggis. 2015. Diversity through specificity: design lessons learned from the Games [4Diversity] Jams. In Proceedings of the 12th International Conference on Advances in Computer Entertainment Technology. Article no. 5.

[12] Pedro Diniz. 2017. Brasil patina no combate à homofobia e vira líder em assassinatos de LGBTs. Folha de São Paulo. Retrieved May, 2017 from https://goo.gl/JIcavi.

[13] Emanuel F. Duarte; M. Cecilia C. Baranauskas. 2016. Revisiting the Three HCI Waves: A Preliminary Discussion on Philosophy of Science and Research Paradigms. In Proceedings of the 15th Brazilian Symposium on Human Factors in Computing Systems. Article no. 38.

[14] Cristiano F. Faria. 2010. Can people help legislators to make better laws?: the Brazilian parliament's e-democracia. In Proceedings of 4th International Conference on Theory and Practice of Electronic Governance, 301-306.

[15] Cally Gatehouse. 2016. Feral Screens: Queering Urban Networked Publics. In Proceedings of the 2016 ACM Conference Companion Publication on Designing Interactive Systems, 99-104.

[16] G1 CE. Travesti Dandara foi apedrejada e morta a tiros no Ceará, diz secretário. G1. Retrieved May, 2017 from https://goo.gl/p2KUr5.

[17] GGB (Grupo Gay da Bahia). 2015. Assassinato de LGBT no Brasil: Relatório 2015. Retrieved April, 2017 from https://goo.gl/Hq5qZO.

[18] Amy Gonzales; Nicole Fritz. 2017. Prioritizing Flexibility and Intangibles: Medical Crowdfunding for Stigmatized Individuals. In Proceedings of the 2017 CHI Conference on Human Factors in Computing Systems, 2371-2375.

[19] Oliver L. Haimson; Anne E. Bowser; Edward F. Melcer; Elizabeth F. Churchill. 2015. Online Inspiration and Exploration for Identity Reinvention. In Proceedings of the 33rd Annual ACM Conference on Human Factors in Computing Systems, 3809-3818.

[20] Oliver L. Haimson; Jed R. Brubaker; Lynn Dombrowski; Gillian R. Hayes. 2015. Disclosure, Stress, and Support During Gender Transition on Facebook. In Proceedings of the 18th ACM Conference on Computer Supported Cooperative Work \& Social Computing, 1176-1190.

[21] Oliver L. Haimson; Jed R. Brubaker; Gillian R. Hayes. 2014 DDFSeeks same: sexual health-related language in online personal ads for men who have sex with men. In Proceedings of the SIGCHI Conference on Human Factors in Computing Systems, 1615-1624.

[22] Jean Hardy; Silvia Lindtner. 2017. Constructing a Desiring User: Discourse, Rurality, and Design in Location-Based Social Networks. In Proceedings of the 17th ACM Conference on Computer Supported Cooperative Work and Social Computing, 13-25.

[23] Christopher. M. Homan; Naiji Lu; Xin Tu; Megan C. Lytle; Vincent M. B. Silenzio. 2014. Social structure and depression in TrevorSpace. In Proceedings of the 17th ACM Conference on Computer Supported Cooperative Work \& Social Computing, 615 625.

[24] Gopinaath Kannabiran; Shaowen Bardzell; Jeffrey Bardzell. 2012. Designing (for) desire: a critical study of technosexuality in HCI. 
In Proceedings of the 7th Nordic Conference on Human-Computer Interaction: Making Sense Through Design, 655-664.

[25] Gopinaath Kannabiran; Marianne G. Petersen. 2010. Politics at the interface: a Foucauldian power analysis. In Proceedings of the 6th Nordic Conference on Human-Computer Interaction: Extending Boundaries, 695-698.

[26] Ann Light. 2011. HCI as heterodoxy: technologies of identity and the queering of interaction with computers. Interacting with computers 23, 5: 430-438.

[27] Kecheng Liu. 2004. Semiotics in information systems engineering. Cambridge University.

[28] Guilherme C. Pereira; M. Cecilia C. Baranauskas. 2015. Opressões de identidade de gênero e orientação sexual percebidas em interfaces de usuário de sistemas digitais: um estudo exploratório. In Proceedings of the 14th Brazilian Symposium on Human Factors in Computing Systems, 93-102.

[29] Joseph G. Ponterotto. 2005. Qualitative Research in Counseling Psychology: A Primer on Research Paradigms and Philosophy of Science. Journal of Counseling Psychology 52, 2: 126-136.

[30] Marina Rossi; Marina Novaes. 2015. Os direitos básicos aos quais transexuais e travestis não têm acesso. El País Brasil. Retrieved April, 2017 from https://goo.gl/58BqJQ.

[31] Gayle Rubin. 1975. The traffic in women: notes on the "political economy" of sex. In Toward an anthropology of women, Rayna R. Reiter. Monthly Review Press.

[32] Rodrigo Sandoval-Almazan; Fabro Steibel. 2013. Benchmarking Mexico \& Brazil open government websites: model and metrics. In Proceedings of the 7th International Conference on Theory and Practice of Electronic Governance, 372-373.

[33] Wanderley P. Sobrinho. 2015. Duas em cada dez empresas se recusam a contratar homossexuais no Brasil. Carta Capital. Retrieved April, 2016 from https://goo.gl/wFKHhC.

[34] Robert Stoller. 1968. Sex and gender: On the development of masculinity and femininity. Science House.

[35] Kleber Tomaz; Cíntia Acayaba. 2015. Travesti fica desfigurada após prisão; Defensoria diz haver indício de tortura. G1. Retrieved May, 2017 from https://goo.gl/8CISN3.

[36] TransgenderEurope. 2015. Trans murder monitoring 15. Retrieved April, 2016 from https://goo.gl/0oYrdY.

[37] Chad Van de Wiele; Stephanie T. Tong. 2014. Breaking boundaries: the uses \& gratifications of Grindr. In Proceedings of the 2014 ACM International Joint Conference on Pervasive and Ubiquitous Computing, 619-630.

[38] Tien E. E. Yeo; T. H. Fung. 2016. Relationships form so quickly that you won't cherish them: mobile dating apps and the culture of instantaneous relationships. In Proceedings of the 7th International Conference on Social Media \& Society. Article no. 2. 